\title{
Tin Soaps in Emulsion PVC Heat Stabilization
}

\author{
ESEN ARKIŞ \\ Department of Chemical Engineering, Faculty of Engineering, Ege University, 35100 Bornova, \\ Izmir, Turkey
}

\section{DEVRIM BALKÖSE}

Department of Chemical Engineering, Faculty of Engineering, Izmir Institute of Technology, Urla, Izmir, Turkey

Received: August 28, 2000

Accepted: September 10, 2001

\begin{abstract}
In this study, the effect of a liquid stabilizer based on organotins on PVC heat stability is investigated. Control and films with tin soap heat stabilizer Sn500K were prepared by solvent casting and they were heated at 160 and $180^{\circ} \mathrm{C}$ for different time periods. X-ray fluorescence spectroscopy analysis showed that tin was present in Sn500K and it was lead-free. DSC analysis showed that glass-transition temperature of films with Sn500K increased from 67 to $75-85^{\circ} \mathrm{C}$ by heating for $15 \mathrm{~min}$ at $180^{\circ} \mathrm{C}$. IR spectroscopy indicated that concentration of carboxylate groups of Sn500K decreased with heating. Films with Sn500K did not degrade for short heating periods; however, degradation occurred in long heating times. Low concentration of Sn500K was recommended, since at high levels incompatibility with PVC and acceleration of degradation was observed. In the high temperature range, control and stabilized samples degraded in the same manner in two steps. (c) 2002 John Wiley \& Sons, Inc. Adv Polym Techn 21: 65-73, 2002; DOI 10.1002/adv.10008
\end{abstract}

KEY WORDS: poly(vinylchloride), stabilization

Correspondence to: Devrim Balköse; e-mail: dbalkose@likya. iyte.edu.tr.

\section{Introduction}

D VC degrades at operating temperatures by the removal of hydrogen chloride. During this degradation, color changes from yellow to orange, 
brown, and black according to the double bond formation. Discoloration starts when the mass loss reaches to $0.1 \% .^{1}$ Degradation occurs, as shown in Eq. (1), by the formation of conjugated double bonds.

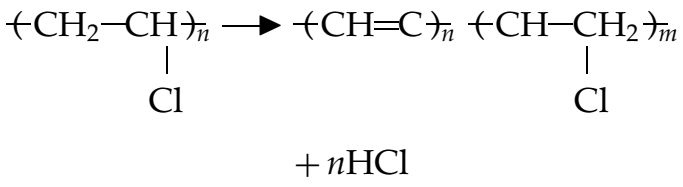

Or in a shorter notation

$$
\mathrm{PVC} \rightarrow \mathrm{dePVC}+n \mathrm{HCl}
$$

where dePVC is dehydrochlorinated PVC which has conjugated double bonds.

Assuming the reaction as first-order with respect to potential double bonds to be formed in PVC, rate of double bond formation

$$
\mathrm{d} C / \mathrm{d} t=-k C,
$$

where $C$ represents concentration of potential double bonds, i.e. $\mathrm{mol} \mathrm{dm}{ }^{-3} \mathrm{HCl}$ in $\mathrm{PVC}$, and $k$ is the first-order reaction rate constant in $\mathrm{min}^{-1}$.

Taking the integral between limits $C=C_{0}$ at $t=0$ and $C=C$ at $t=t$, we have

$$
\ln \left(C_{0} / C\right)=k t
$$

Thus, conversions at any time can be found by this integrated rate equation.

Knumann and Bockhorne ${ }^{2}$ compared PVC and other polymers by TGA. They investigated the kinetics of pyrolysis of PVC and found a dehydrochlorination reaction order to be 1.5. Gupta and Viswanath ${ }^{3}$ studied the role of metal oxides in PVC degradation by TGA and proposed that the reaction was in two steps, and the rate-controlling step was the formation of metal chloride. $\mathrm{Wu}$ et al. ${ }^{4}$ studied the pyrolysis of PVC in the temperature range of 400$500 \mathrm{~K}$ by TGA. The entire process of pyrolysis was in two stages; thermal dehydrochlorination and the breakdown of the intermediate products produced after the dehydrochlorination stage. The pyrolysis behavior of PVC at high conversion was explained by a competitive reaction model with the production of volatiles and char. ${ }^{5}$

According to the Frye-Horst mechanism, ${ }^{6}$ dehydrochlorination of PVC is prevented by metal soaps, with the substitution of labile chlorine atoms of PVC by carboxylate groups of the metal-soap-forming ester groups.

Garrigues et al. ${ }^{7}$ compared the thermal dehydrochlorination of PVC in the presence of dialkyl tin maleates and laurates in 1,2,4-trichlorobenzene solution by IR analysis, and they proved the superiority of tin maleates over tin laurates in the substitution reaction. Their attempts to trace intermediate monochlorotin derivatives in the case of maleates by polarography and Mössbauer spectroscopy were not conclusive. Rujian et al. ${ }^{8}$ reported that dibutyltin laurate (DBTDL) prevented the formation of longer polyene lengths, and coloration of PVC was retarded effectively in this way. DBTDL cannot prevent the formation of shorter polyene length. Thermal dehydrochlorination still occurred but its rate was decreased and longer polyenes were formed. ${ }^{8}$ There was no change in color of the PVC films with a commercial organo tin stabilizer with trade nameSn500K at $160^{\circ} \mathrm{C}$ for $105 \mathrm{~min} .{ }^{9}$ Sterically hindered phenolic antioxidants were used together for long-time stabilization of PVC. ${ }^{10}$

PVC heat stabilizers are sold on the market under trade names and no information about their exact composition are given by their producers. Leadfree stabilizers gained importance in recent years because of the harmful effects of lead on health. Thermal stabilization of the PVC under this study by using lead-free stabilizers, epoxidized soybean oil, and zinc stearate was investigated before. ${ }^{11}$ Low transparency, good thermal stability at $140^{\circ} \mathrm{C}$, but accelerated degradation at higher temperature and at long heating times because of accumulation of $\mathrm{ZnCl}_{2}$ acting as a catalyst for dehydrochlorination were observed. The solid state of zinc stearate in PVC films at the temperatures studied prevented formation of a homogeneous mixture at the molecular level, causing inefficient thermal stabilization. Thus, a liquid-lead-free heat stabilizer having an organotin compound with trade name $\mathrm{Sn} 500 \mathrm{~K}$ was chosen as a representative example to show how a heat stabilizer can be characterized both in composition and in efficiency. Higher thermal stabilization efficiency was expected since better mixing of the liquid stabilizer with PVC would be obtained.

\section{Experimental}

In this study, emulsion PVC (PETVINYL P38/74 from Petkim, Turkey with number average molecular weight 50,000) was used. PVC was produced 
by spray-drying of the PVC latex from the emulsion polymerization, and it contained all the emulsifying ingredients. Liquid organotin stabilizer (Sn500K from Farstab stabilizer company, Turkey) and tetrahydrofuran (THF), $\mathrm{C}_{4} \mathrm{H}_{8} \mathrm{O}$, stabilized with antioxidant and butylated hydroxytoluene (BHT) (from Merck) were used in the film preparation, together with PVC.

The organotin stabilizer was analyzed by $\mathrm{x}$-ray fluorescence analysis using the Jeol X-ray Fluorescence Spectrometer. The ash content was also determined after carbonizing in air and heating at $900^{\circ} \mathrm{C}$ till constant weight.

In the studied samples, 2.5 and 5\% Sn500K were added to PVC. Sample preparation was done using solvent casting method. After mixing $6 \mathrm{~g}$ of $\mathrm{PVC}$ with 0.15 and $0.30 \mathrm{~g}$ of $\mathrm{Sn} 500 \mathrm{~K}$ in $125 \mathrm{~cm}^{3}$ of THF, they were allotted to 10 petri dishes. THF has high vapor pressure at $25^{\circ} \mathrm{C}$ and it boils at $65-66^{\circ} \mathrm{C}^{12}$ After allowing for evaporation of THF for one day, PVC film samples with tin stabilizers and BHT were obtained. All films contained $0.49 \%$ antioxidant, BHT introduced with THF, and a small amount of THF. Since BHT melts at $69-70^{\circ} \mathrm{C}$ and boils at $265^{\circ} \mathrm{C}$, it was present in PVC films at $25^{\circ} \mathrm{C}$ in solid state. ${ }^{12}$

Films were exposed to heat by static oven method at 160 and $180^{\circ} \mathrm{C}$ for $105 \mathrm{~min}$.

A Shimadzu IR Spectrophotometer and a Jasco 750 UV Spectrophotometer were used to obtain transmission IR and UV spectra of the films. IR spectrum of a liquid film of $\mathrm{Sn} 500 \mathrm{~K}$ on $\mathrm{KBr}$ disc was also taken. A Setaram 92 DSC Colorimeter and a DuPont TGA Analyzer were used for thermal analysis. The samples were heated at $10^{\circ} \mathrm{C} \mathrm{min}$, heating rate in the ranges of $25-200^{\circ} \mathrm{C}$ and $30-500^{\circ} \mathrm{C}$ for DSC and TGA respectively.

The yellowness index of the films was determined using $X-Y-Z$ parameters of the films placed on $\mathrm{MgO}$ white standard of Muruyama Color Machine.

\section{Results}

\section{Sn500K CHARACTERIZATION}

By $x$-ray fluorescence spectroscopic analysis, tin was detected in $5 n 500 K$. There was a reflection showing the presence of tin at $2 \theta=14.04$ with LiF crystal. No Pb peak was found at $2 \theta=33.93$ with $\mathrm{LiF}$ crystal. ${ }^{13,14}$ Thus, Sn500K was a stabilizer containing tin without lead. It contained $8.1 \%$ tin as indicated by its ash content.

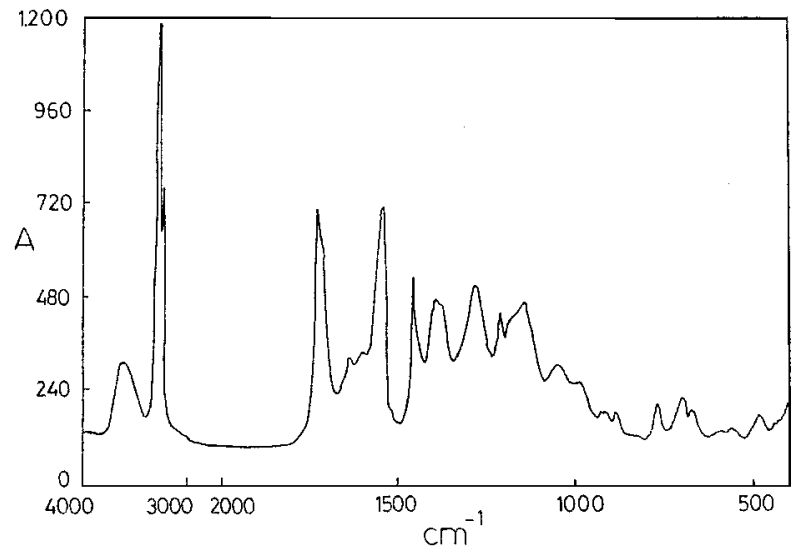

FIGURE 1. IR spectrum of Sn500K.

The IR spectrum of Sn500K in Fig. 1 indicated the presence of $\mathrm{C}=\mathrm{O}$ groups at $1720 \mathrm{~cm}^{-1}$, double bonds at 1600 and $1640 \mathrm{~cm}^{-1}$, and $\mathrm{COO}^{-}$groups at $1540 \mathrm{~cm}^{-1}$. Although the spectrum of Sn500K was very similar to that of dibutyltinbis(isooctyl maleate) (DBTIOM) given by Wypich ${ }^{15}$, Sn500K contained a smaller amount of tin, $8.1 \%$ as compared to the $11.5 \%$ of butyltinbis(isooctyl maleate) had. Thus, there should also be a diluting solvent in Sn500K.

\section{EFFECT OF Sn500K ON PVC DEGRADATION}

\section{Yellowness Index and Transparency}

The films having Sn500K had lower yellowness index than that of the control film heated at different periods at 160 and $180^{\circ} \mathrm{C}$, as seen in Fig. 2. The higher the $\mathrm{Sn} 500 \mathrm{~K}$ concentration and the heating temperature were, the higher was the yellowness index. The color of the film with $2.5 \%$ Sn $500 \mathrm{~K}$ had a very small yellowness index up to $30 \mathrm{~min}$ time both at 160 and $180^{\circ} \mathrm{C}$, indicating that a safe induction period for dehydrochlorination was present. The heat stability temperature range of the PVC under study was higher for Sn500K than for zinc stearate and epoxidized soybean oil stabilizers. ${ }^{11}$

While the control and 2.5\% Sn500K-containing films were transparent, films with $5.0 \%$ Sn500K were opaque white, indicating limited solubility of Sn500K in PVC.

\section{DSC Analysis}

From DSC curves seen in Fig. 3, the glasstransition temperature $\left(T_{\mathrm{g}}\right)$ of unheated PVC was 


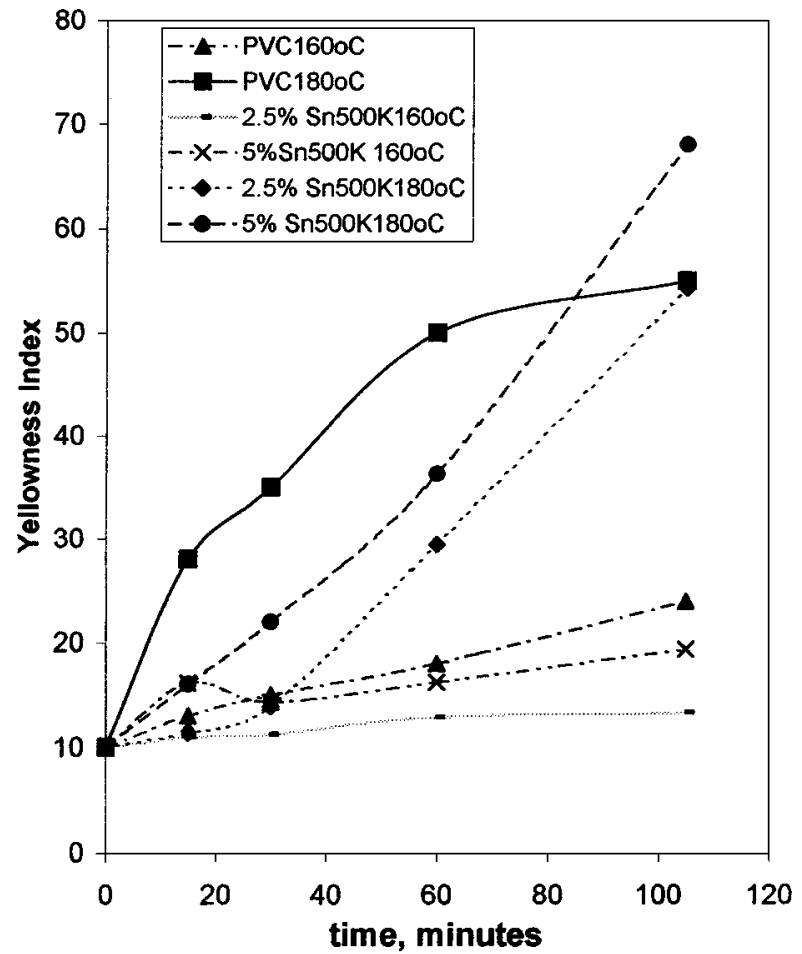

FIGURE 2. Yellowness index of films versus heating time.

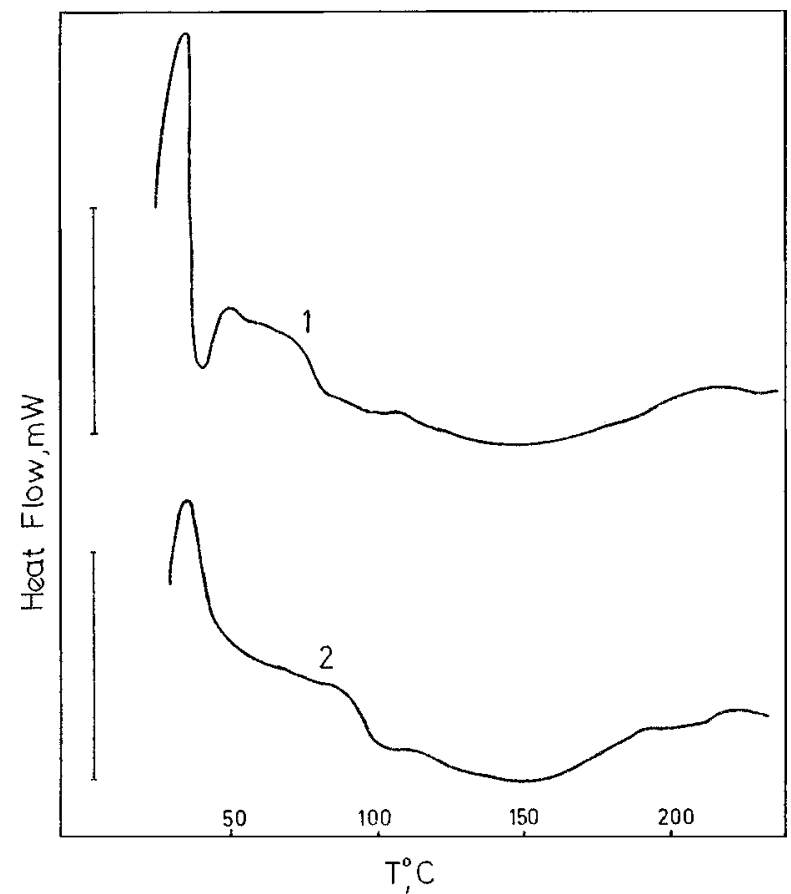

FIGURE 3. DSC curves for PVC. (1) $26.70 \mathrm{mg}$ unheated and (2) $31.20 \mathrm{mg}$ heated at $180^{\circ} \mathrm{C}$ for $60 \mathrm{~min}$. I represents $4 \mathrm{mWs}$.

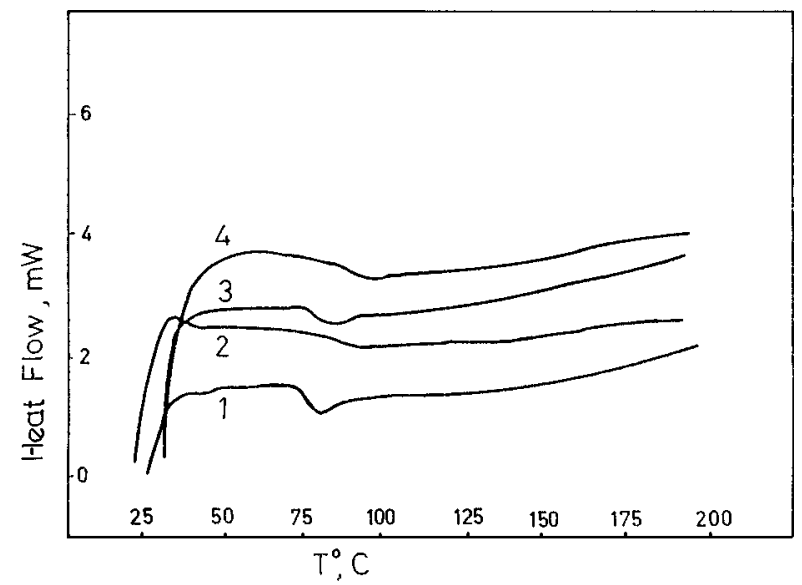

FIGURE 4. DSC curves for PVC with Sn500K.

(1) Unheated $2.5 \%$ Sn500K, (2) $2.5 \%$ Sn500K heated at $180^{\circ} \mathrm{C}$ for $105 \mathrm{~min}$, (3) Unheated $5 \%$ Sn500K, and (4) $5 \%$ Sn500K heated at $180^{\circ} \mathrm{C}$ for $105 \mathrm{~min}$.

$67^{\circ} \mathrm{C}$ and the glass-transition temperature of PVC heated at $180^{\circ} \mathrm{C}$ for $60 \mathrm{~min}$ was $92^{\circ} \mathrm{C}$. By heating at $180^{\circ} \mathrm{C}$ for $60 \mathrm{~min}$, the THF acting as a plasticizer was removed from the films and the glass-transition temperature was increased. As seen in DSC curves of films with Sn500K, the glass-transition temperature for unheated film increased from 67 to $75-85^{\circ} \mathrm{C}$ by heating the film at $180^{\circ} \mathrm{C}$ for $105 \mathrm{~min}$ (Fig. 4). A small endotherm observed near the glass-transition temperature could be attributed to the heat of evaporation of THF from the films. Sn500K also had a plasticizing action on PVC since $T_{\mathrm{g}}$ points of $S n 500 \mathrm{~K}$ containing films as seen in Fig. 4 were not as sharp as the $T_{\mathrm{g}}$ points of control films as seen in Fig. 3 .

\section{IR Analysis}

In the IR spectrum of PVC in Fig. 5a, $2965 \mathrm{~cm}^{-1}$ as $\mathrm{CH}$ stretch, $2910 \mathrm{~cm}^{-1}$ as $\mathrm{CH}_{2}$ stretch, $1425 \mathrm{~cm}^{-1}$ as $\mathrm{CH}_{2}$ bending, $1098 \mathrm{~cm}^{-1}$ as C-C vibration, $970 \mathrm{~cm}^{-1}$ as $\mathrm{CH}_{2}$ rocking, $690 \mathrm{~cm}^{-1}$ as $\mathrm{CCl}$ isotactic stretch, and $603-698 \mathrm{~cm}^{-1}$ as $\mathrm{CCl}$ syndiotactic stretch vibrations were observed. The decrease of $\mathrm{C}-\mathrm{O}-\mathrm{C}$ band for THF at $1060 \mathrm{~cm}^{-1}$ (Fig. 5b) by heating of PVC film indicated the removal of THF from PVC.

With increasing time and temperature of heating, the band intensity for $\mathrm{COO}^{-}$groups at $1540 \mathrm{~cm}^{-1}$ decreased for the films with Sn500K, as seen in Figs. 6 and 7 and in Table I. Reaction of stabilizer with PVC can be shown as follows:

$$
\begin{aligned}
& \mathrm{CH}_{2}-\mathrm{CHCl}-\mathrm{CHCl}-\mathrm{CHClCH}_{2} \mathrm{CHCl}-\mathrm{X}- \\
& +\left(\mathrm{R}_{2} \mathrm{COO}\right)_{2} \mathrm{Sn}\left(\mathrm{R}_{1}\right)_{2}
\end{aligned}
$$




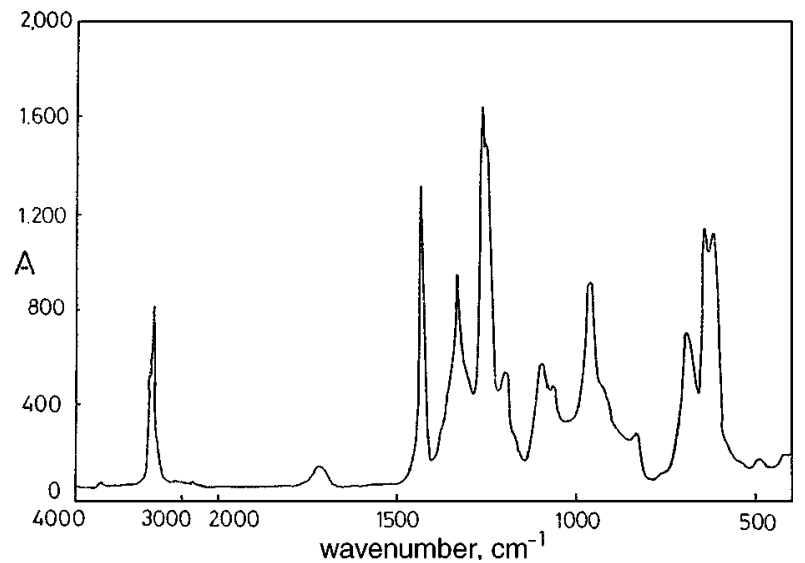

FIGURE 5a. IR spectrum of unheated PVC.

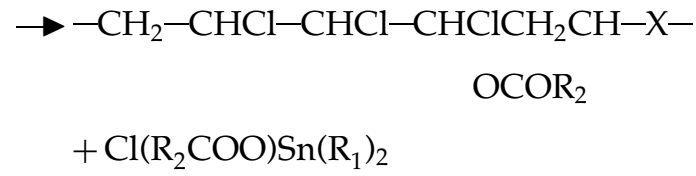

where $\left(\mathrm{R}_{2} \mathrm{COO}\right)_{2} \mathrm{Sn}\left(\mathrm{R}_{1}\right)_{2}$ is the suggested formula of the active ingredient.

Further reaction of stabilizer with PVC was expected to end with $\mathrm{Cl}_{2} \mathrm{Sn}\left(\mathrm{R}_{1}\right)_{2}$.

The labile chlorine atoms of PVC were substituted by carboxylate groups of organotin soap forming stable ester groups, according to the Frye-Horst mechanism. ${ }^{6}$

Decrease of intensity of $1720 \mathrm{~cm}^{-1}$ and $1640 \mathrm{~cm}^{-1}$ bands as reported in Table I indicated the removal of carbonyl groups and groups having double bonds by evaporation of Sn500K from films on

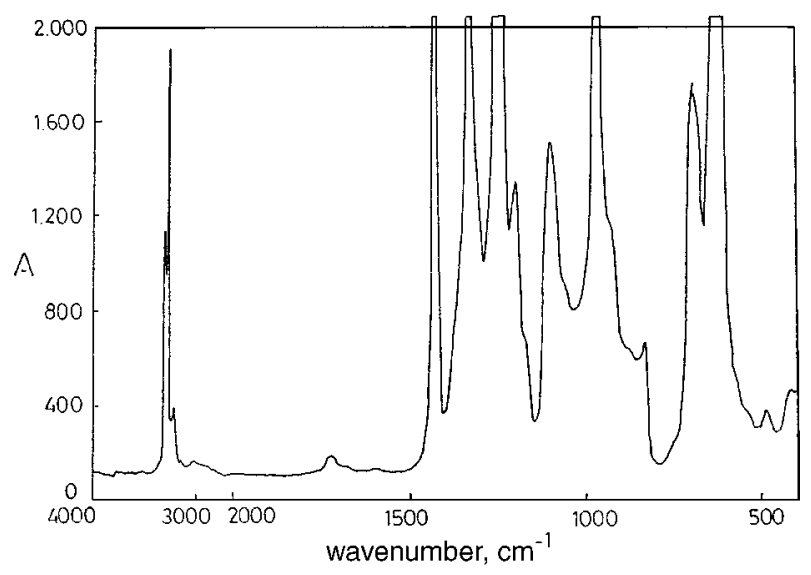

FIGURE 5b. IR spectrum of PVC heated at $180^{\circ} \mathrm{C}$ for 60 min.

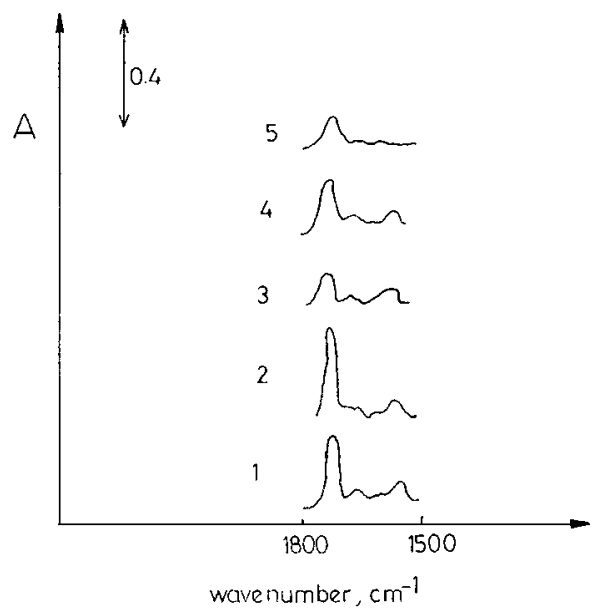

FIGURE 6. IR spectra of samples with $2.5 \%$ Sn500K for the $1500-1800 \mathrm{~cm}^{-1}$ range: (1) unheated, (2) heated at $160^{\circ} \mathrm{C}$ for $15 \mathrm{~min}$, (3) heated at $160^{\circ} \mathrm{C}$ for $105 \mathrm{~min}$, (4) heated at $180^{\circ} \mathrm{C}$ for $15 \mathrm{~min}$, and (5) heated at $180^{\circ} \mathrm{C}$ for $105 \mathrm{~min}$.

heating. Sn500K was volatile similar to DBTIOM, which evaporates in the range of $445-523 \mathrm{~K}^{15}$ The characteristic vibration of $-\mathrm{C}=\mathrm{C}-$ bonds in polyene sequences at $1630 \mathrm{~cm}^{-1}$ was observed to be increasing with heating time after the induction period for PVC stabilized with DBTDL. ${ }^{7}$ Since the band intensity at $1640 \mathrm{~cm}^{-1}$, which was very close to the $1630 \mathrm{~cm}^{-1}$ band, was decreased with heating time, the polyene sequences formed by heating Sn500Kstabilized PVC was not at a concentration level that could be detected by IR spectroscopy.

\section{UV Analysis}

It is possible to calculate percent conversions related to a number of double bonds that may be formed by dehydrochlorination from the UV spectra of the films. Total concentration of 6-10 conjugated double bonds were found using the absorbance and molar absorption coefficients of different polyene types. ${ }^{16}$

The concentration of polyene sequences is given by

$$
C_{n}=A /\left(\varepsilon_{\lambda} d\right)
$$

where $A$ is the absorbance at wavelength $\lambda, \varepsilon_{\lambda}$ is the extinction coefficient, $n$ is the number of congugated double bonds, and $d$ is the path length of the cell. ${ }^{17}$ $\varepsilon_{\lambda}$ values given by Shindo and Hirai ${ }^{16}$ were used in $\mathrm{C}_{n}$ calculations. 


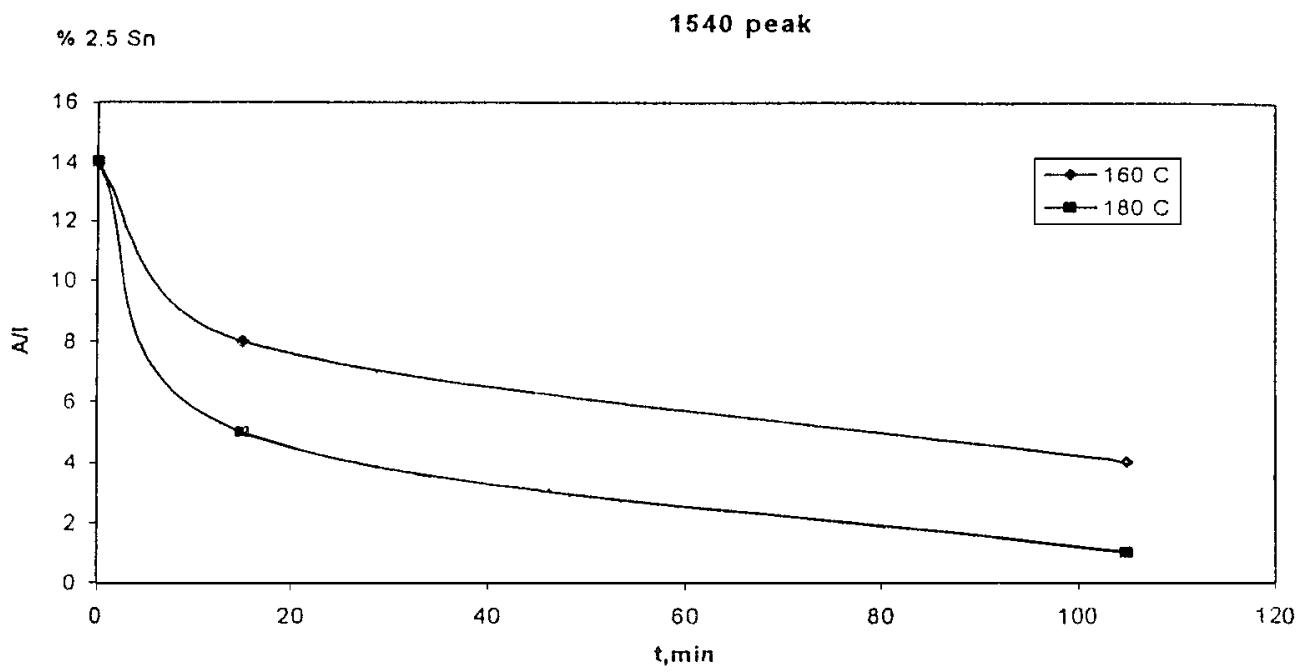

FIGURE 7. Change of absorbance of $1540 \mathrm{~cm}^{-1}$ peak with time and heating film with $2.5 \%$ Sn500K.

The mole fraction of polyene sequences containing $n$ conjugated double bonds can be determined from $\mathrm{C}_{n}$ as

$$
N_{n}=C_{n} / C
$$

where $C$ is the concentration of vinyl repeat units in $\mathrm{mol} / \mathrm{dm}^{3}$. Mole fraction of double bonds

$$
N_{\mathrm{D}}=\sum n N_{n}
$$

For tin-stabilizer-containing films, UV absorption of the stabilizer also overlapped with conjugated double bond peaks up to $300 \mathrm{~nm} .{ }^{16}$ For solid PVC having $1.4 \mathrm{~g} / \mathrm{cm}^{3}$ density, $C$ was $22.2 \mathrm{~mol} / \mathrm{dm}^{3}$.
Since there was a peak of BHT at $275 \mathrm{~nm}$, which overlaps the peaks of up to six conjugated -enes and Sn500K also absorbed UV light in the same range, the total number of double bonds having six and more than six double bonds were calculated using UVspectra and Eqs. (4)-(6). Percent conversion of available repeat units to double bonds by dehydrochlorination equals to $100 N_{\mathrm{D}}$.

Representative UV spectra of the films are given in Figs. 8 and 9. Percent conversions found for PVC, PVC with 2.5\% Sn500K, and PVC with 5\% Sn500K from UV spectra and their colors are given in Table II. Smaller conversion of PVC with $2.5 \%$ Sn500K than of PVC alone was observed. PVC without any additive became brown on heating at $180^{\circ} \mathrm{C}$ for $105 \mathrm{~min}$,

TABLE I

Absorbances of Characteristic Peaks in IR Spectra of PVC-Sn500K Films

\begin{tabular}{cccccc}
\hline Film & Temperature $\left({ }^{\circ} \mathrm{C}\right)$ & Time $(\mathrm{min})$ & $1540 \mathrm{~cm}^{-1}$ & $1640 \mathrm{~cm}^{-1}$ & $1720 \mathrm{~cm}^{-1}$ \\
\hline $2.5 \%$ Sn500K & \multirow{3}{*}{160} & 0 & 0.14 & 0.08 & 0.36 \\
& & 15 & 0.08 & 0.04 & 0.33 \\
& 105 & 0.04 & 0.03 & 0.11 \\
& 180 & 15 & 0.05 & 0.04 & 0.21 \\
$5 \%$ Sn500K & 105 & 0.01 & 0.01 & 0.13 \\
& \multirow{2}{*}{160} & 0 & 0.20 & 0.10 & 0.33 \\
& 150 & 15 & 0.12 & 0.10 & 0.30 \\
& 105 & 0.13 & 0.07 & 0.13 \\
& 15 & 0.16 & 0.11 & 0.20 \\
& & 105 & 0.06 & 0.04 & 0.17 \\
\hline
\end{tabular}




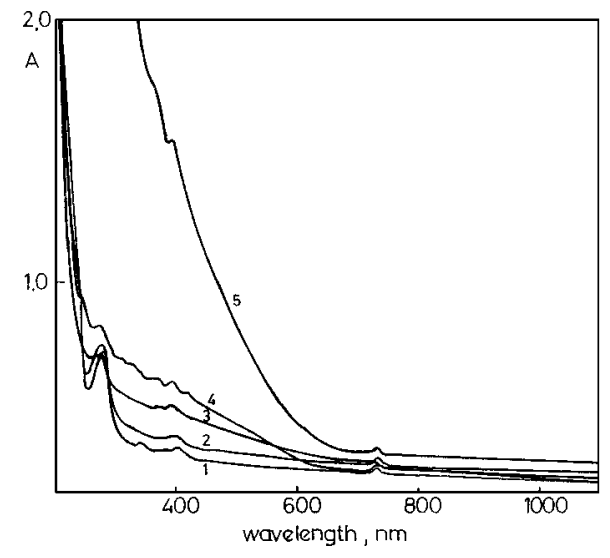

FIGURE 8. UV spectra for PVC: (1) unheated, (2) heated at $160^{\circ} \mathrm{C}$ for $15 \mathrm{~min}$, (3) heated at $160^{\circ} \mathrm{C}$ for $60 \mathrm{~min}$, (4) heated at $180^{\circ} \mathrm{C}$ for $15 \mathrm{~min}$, and (5) heated at $180^{\circ} \mathrm{C}$ for $60 \mathrm{~min}$.

indicating it was degraded with the formation of long polyene sequences. On the other hand, the white color of the unheated films with $5 \%$ Sn500K in Table II indicated that PVC was not degraded. The opaque and white color of the unheated films appeared to have superficially high $\%$ conversion $[1.8 \%$ found from Eq. (6) as reported in Table II]. Thus, the conversion determination from Eq. (6) should be correct only for transparent samples. Since films were

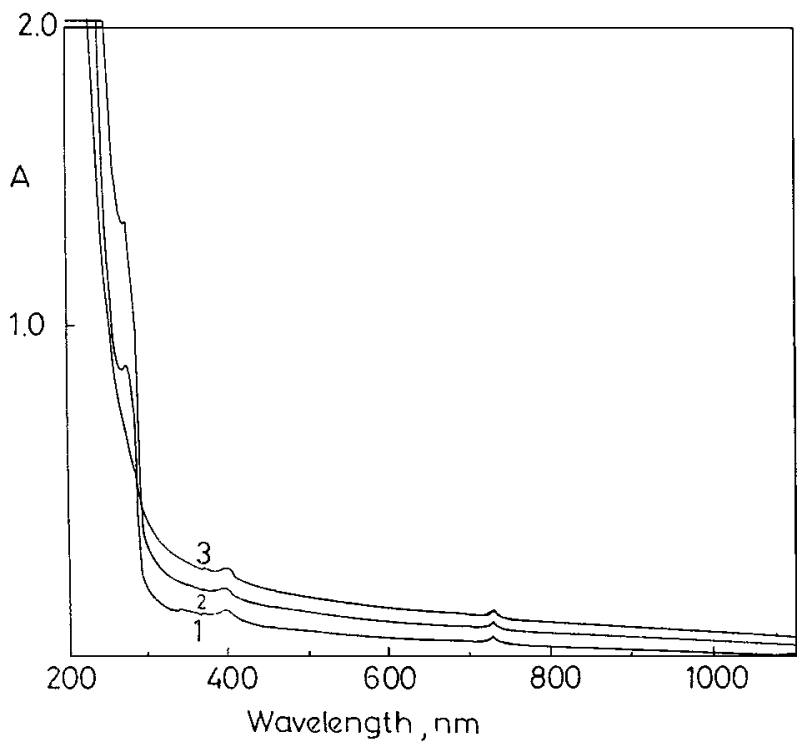

FIGURE 9. UV spectra of samples with $2.5 \%$ Sn500K: (1) unheated, (2) heated at $160^{\circ} \mathrm{C}$ for $15 \mathrm{~min}$, and (3) heated at $160^{\circ} \mathrm{C}$ for $60 \mathrm{~min}$. not transparent the UV analysis did not give reliable results.

\section{TGA}

The thermograms of the film samples shown in Fig. 10 indicate that there is a step mass loss around the glass-transition temperature of the films because of THF evaporation. This also confirmed that endotherm observed around the glass-transition point belonged to THF evaporation. The stabilizing effect of BHT and Sn500K on PVC above $175^{\circ} \mathrm{C}$ was observed, since the mass loss from PVC powder is much faster than the mass loss from cast PVC films.

Activation energy $E_{\mathrm{a}}$, Arrhenius constant $A$, and degradation rate coefficient $k$ can be found from the following equation:

$$
\begin{aligned}
k & =A \exp \left(-E_{\mathrm{a}} / R T\right) \\
\ln \left[(\mathrm{d} \alpha / \mathrm{d} T) /(1-\alpha)^{n}\right] & =\ln (A / \beta)-E_{\mathrm{a}} / R T
\end{aligned}
$$

taking the reaction order to be 1 and by taking temperatures and mass loss \% (a) from TGA curves. $\alpha$ values, conversions, were taken as $(100-a / 58) / 100$, where 58 is the weight \% of $\mathrm{HCl}\left(C_{0}\right)$ in PVC and $a$ is the percentage of remaining mass of the sample at temperature T. $\beta$ is the heating rate expressed in degrees per minute. The slope and the intercept of the $\ln \left[(\mathrm{d} \alpha / \mathrm{d} T] /(1-\alpha)^{n}\right)$ vs. $1 / T$ line is $-E_{\mathrm{a}} / R$ and $\ln (A / \beta)$, respectively. $k$ values at $180^{\circ} \mathrm{C}$ were found using $E$ and $A$ values found from TGA.

Conversions found from UV analysis were lower than conversions from TGA, using Eq. (3), because of the evaporation of THF, and Sn500K present in the films occurred as well as PVC degradation (Table III).

As seen in Table IV, the PVC film and samples with $5 n 500 K$ have lower $k$ values than PVC powder. Antioxidant BHT acted as heat stabilizer since it was a radical acceptor. ${ }^{10}$ Only the rate of formation of polyene sequences longer than 6 units was included in UV analysis, excluding shorter polyene sequences because of the overlapping of the BHT and $\mathrm{Sn} 500 \mathrm{~K}$ spectra in their range. Higher conversion found form TGA represented all $\mathrm{HCl}$ molecules splitted from PVC, including short and long polyene sequences. The present study also confirmed the formation of short polyene sequences with organotin stabilizers, as reported by previous workers. ${ }^{8}$

It was observed that the sample with $2.5 \% \mathrm{Sn} 500 \mathrm{~K}$ was less degraded than the sample with 5\% Sn500K. The level of Sn500K in the films should be kept low to have transparent films. At high Sn500K 
PVC STABILIZATION BY ORGANO TIN SOAPS

TABLE II

Percent Conversions from UV Analysis for PVC, PVC $+2.5 \%$ Sn500K and PVC $+5 \%$ Sn500K

\begin{tabular}{ccccccc}
\hline Additive Type & $\begin{array}{c}\text { Percent } \\
\text { Additive }(\%)\end{array}$ & $\begin{array}{c}\text { Film } \\
\text { Thickness }(\mu)\end{array}$ & $\begin{array}{c}\text { Heating } \\
\text { Temperature }\left({ }^{\circ} \mathrm{C}\right)\end{array}$ & $\begin{array}{c}\text { Heating } \\
\text { Time }(\min )\end{array}$ & $\begin{array}{c}\text { Percent } \\
\text { Conversion }\end{array}$ & $\begin{array}{c}\text { Color } \\
-\end{array}$ \\
\hline- & - & 4 & 160 & Unheated & 0.155 & Transparent \\
Sn500K & 2.5 & 8 & 180 & 15 & 0.354 & Brown \\
Sn500K & 2.5 & 5 & 160 & Unheated & 0.204 & Transparent \\
Sn500K & 5 & 9 & 180 & 15 & 0.219 & Transparent \\
Sn500K & 5 & 3 & 160 & Unheated & 1.830 & White \\
\hline
\end{tabular}

concentrations, films become opaque white because of the incompatibility of Sn500K and PVC.

In the high temperature range, Sn500K did not effect degradation of PVC. As seen in Fig. 10, degradation occurred in two steps, as observed by previous workers. ${ }^{4,5}$ At $425^{\circ} \mathrm{C}$ the remaining mass of PVC was in the range of $17-25 \%$ for control and stabilized films.

\section{Discussion and Conclusion}

The exact composition of PVC stabilizers was not revealed by their producers. Using x-ray fluorescence analysis, it is possible to find out which met-

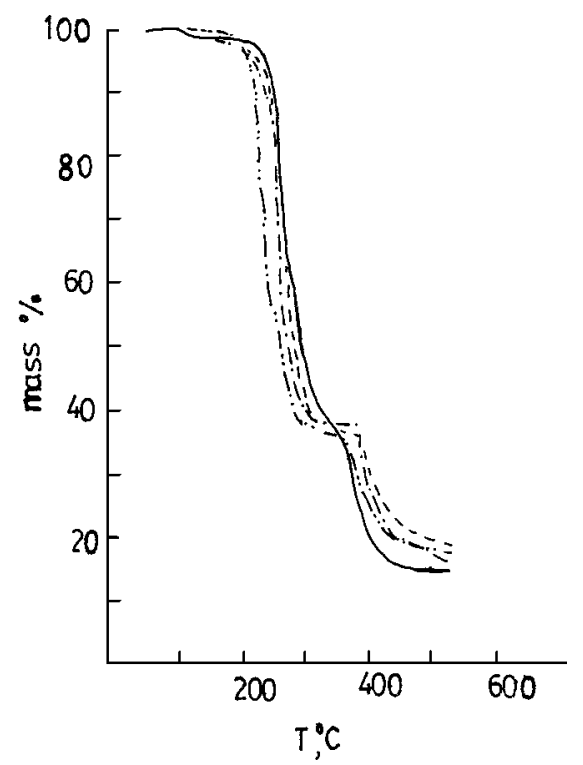

FIGURE 10. TGA curves for PVC powder (---), PVC film (-), PVC film with $2.5 \%$ stabilizer (---), and PVC film with $5 \%$ stabilizer $(-)$. als are present in any stabilizer. IR spectroscopy can be used to find out the functional groups that are effective in PVC stablization. Thus, Sn500K was chosen as a representative liquid heat stabilizer and was analyzed to find out that it was a lead free, and was containing tin element. It is most probably DBTOM dissolved in a solvent.

The heat stability tests of films with Sn500K showed an induction period up to $30 \mathrm{~min}$ in terms of yellowing. Actually, shorter polyene sequences, ${ }^{8}$ which did not discolor PVC, were formed as indicated by UV spectroscopy.

At low temperatures $\left(160^{\circ} \mathrm{C}\right)$ and short heating times (15 min) films having $2.5 \% \mathrm{Sn} 500 \mathrm{~K}$ were more stable than PVC powder and PVC film without additive with respect to color, double bond formation, and rate of mass loss. For longer heating periods, Sn500K has not enough effectiveness. The effects of THF on glass-transition temperature and BHT on thermal stability were also observed. DSC and TGA showed that THF was evaporated from the films by heating at glass-transition temperature of the films. In film preparation, transparent coatings of PVC stable to heat for short periods could be obtained by using low Sn500K content. In the high temperature range of heating, Sn500K had no effect on the degradation behavior of PVC.

TABLE III

Percent Conversion of PVC to dePVC for Heating at $180^{\circ} \mathrm{C}$ for $15 \mathrm{~min}$ as Determined by UV Spectroscopy and TGA

\begin{tabular}{lcc}
\hline & \multicolumn{2}{c}{ Percent Conversion } \\
\cline { 2 - 3 } Sample & TGA & UV \\
\hline PVC film & 4.2 & 0.354 \\
$2.5 \%$ Sn & 4.7 & 0.219 \\
$5 \%$ Sn & 9.9 & 1.130 \\
\hline
\end{tabular}


TABLE IV $E_{\mathrm{a}}, A$ Values, and $k$ Degradation Constants at $180^{\circ} \mathrm{C}$

\begin{tabular}{lccc}
\multicolumn{1}{c}{ Sample } & $E_{\mathrm{a}}(\mathrm{J} / \mathrm{mol})$ & $A$ & $k(1 / \mathrm{s})$ \\
\hline PVC powder & 91750.71 & $1.04 \times 10^{9}$ & 0.020597 \\
PVC film & 82790.87 & $1.26 \times 10^{7}$ & 0.002769 \\
$2.5 \%$ Sn500K & 118151.6 & $2.29 \times 10^{11}$ & 0.003774 \\
5\% Sn500K & 83573.67 & $4.02 \times 10^{7}$ & 0.007160 \\
\hline
\end{tabular}

Higher thermal stabilization efficiency was obtained with Sn500K compared to the zinc stearate stabilizer, ${ }^{11}$ since better mixing of the liquid stabilizer with PVC had been possible.

\section{References}

1. Nass, L. I. Encyclopedia of Chemical Technology, Vol. 12; Wiley: New York, 1979.

2. Knumann, R.; Bockhorn, H. Combust Sci Technol 1994, 101, 285.

3. Gupta, M. C.; Viswanath, S. G. Ind Eng Chem Res 1994, 37, 2707.
4. Wu-Ch; Chang, C. Y.; Hor, J. I.; Shih, S. M.; Chen, L. W.; Chang, F. W. Can J Chem Eng 1994, 72, 644.

5. Wu-Ch; Chang, C. Y.; Hor, J. I.; Shih, S. M.; Chen, L. W. Chem Eng J 1994, 55, 87.

6. Frye, A. H.; Horst, R. W. J Polym Sci 1959, 40, 419.

7. Garrigues, C.; Guyot, A.; Tran, V. H. Polym Degrad Stab 1994, 43, 299.

8. Ruijian, X.; Dafei, Z.; Deren, Z. Polym Degrad Stab 1989, 27, 203.

9. Balköse, D.; Ari, Ş.; İçten, N. Diploma Project, Faculty of Chemical Engineering, Ege Üniversity 1989 (in Turkish).

10. Kovaric, P.; Klein, E.; Volka, L. Chem Pap 1997, 51, 245.

11. Baltacioğlu, H.; Balköse, D. J Appl Polym Sci 1999, 74, 2428.

12. Weast, R. C.; Astle, M. J. CRC Handbook of Chemistry and Physics; Chemical Rubber Publishing Company: Florida, 1980.

13. Fang, H. J.; Blass, F. D. X-Ray Diffraction Tables; Southern Illinois University Press: Illinois, 1966.

14. Joint Committee on Powder Diffraction Standards, Powder Diffraction Files; Philadelphia, PA, 1967.

15. Wypich, J. Polyvinyl Chloride Stabilization; Elsevier: New York, 1986.

16. Shindo, Y.; Hirai, T. Makromol Chem 1972, 155, 1.

17. Patel, K.; Velasquez, A.; Calderon, H. J. J Appl Polym Sci $1992,46,179$. 